\title{
Response Characteristics Analysis and Optimization Design of Load Sensing Variable Pump
}

\author{
Hong-Xin Cui, Ke Feng, Huan-Liang Li, and Jin-Hua Han \\ College of Field Engineering, PLA University of Science and Technology, Nanjing 210007, China \\ Correspondence should be addressed to Ke Feng; fengke0430@163.com
}

Received 21 May 2016; Revised 1 August 2016; Accepted 14 August 2016

Academic Editor: Mohammed Nouari

Copyright ( 2016 Hong-Xin Cui et al. This is an open access article distributed under the Creative Commons Attribution License, which permits unrestricted use, distribution, and reproduction in any medium, provided the original work is properly cited.

\begin{abstract}
This paper aimed to decrease damping coefficient and enhance dynamic performance of the load sensing variable pump. Firstly, the working mechanism of the pump was analyzed and the dynamic model was built; hence it was concluded that the method to improve the system performance is to increase corner frequency of the first-order inertia elements. Then the simulation test rig of the load sensing variable pump was built with SimHydraulics software and was verified by simulation and experiments; the influence rules of main parameters on the system performance were studied by dynamic simulations. Finally, a structure optimization scheme was proposed; simulation results show that the response time of optimized system is $33.42 \%$ reduced and flow overshoot has fallen down from $8.9 \%$ to $1.6 \%$ compared with the original system.
\end{abstract}

\section{Introduction}

Load sensing variable pump consists of main pump and control valves, control valves can automatically adjust pump output flow and pressure to match the load, and this avoids overflow loss and throttling loss. So load sensing variable pump has the characteristics of low energy loss and high efficiency and is increasingly popular in engineering machinery. In order to advance the pump performance and operating stability, it is very important to optimize the pump structure. Because of the complexity of the load sensing variable pump's structure, the accurate mathematical model is difficult to be established. Therefore, the traditional development methods are difficult to meet the design requirements of modern pump.

The application of computer simulation technology $[1,2]$ brings people a convenient and efficient way to design the pump. By simulation tests, engineers can not only discover the potential design problems and modify them in time but also alleviate the dependence on physical prototype. The virtual simulation technology can greatly simplify the development process, shorten the development cycle, reduce the cost, and get the optimal design scheme [3, 4]. In recent years, the virtual simulation technology has been applied to the development of hydraulic pump and made some valuable achievement $[5,6]$. Cho et al. $[7,8]$ used the AMESim software to establish the virtual simulation model of a bentaxis type piston pump and analyzed the pressure ripple characteristics and the piston behavior according to eccentricity ratio of the disk. Bergada et al. [9] studied axial-piston pump leakage and output flow ripples based on the dynamic characteristics of the pump. Casoli and Anthony [10] built an excavator's variable displacement hydraulic pump model based on gray box and achieved fast simulation of excavation cycles. Mandal et al. [11] studied pressure compensator design method for a swash plate axial-piston pump. Xu et al. [12] investigated on structural optimization of antioverturning slipper of axial-piston pump to improve the service life and the reliability of the piston pump. Roccatello et al. [13] built multibody simulation model of a variable displacement axialpiston pump based on software interface technology and analyzed the dynamic response characteristics of the pump. Zhu et al. [14] analyzed response performances of a load sensing pump; however, research is still at a preliminary stage; a lot of work is still to be done. Although domestic and foreign scholars have conducted many studies, there is few literature focus on the structure and parameters optimization of the load sensing variable pump $[15,16]$. 


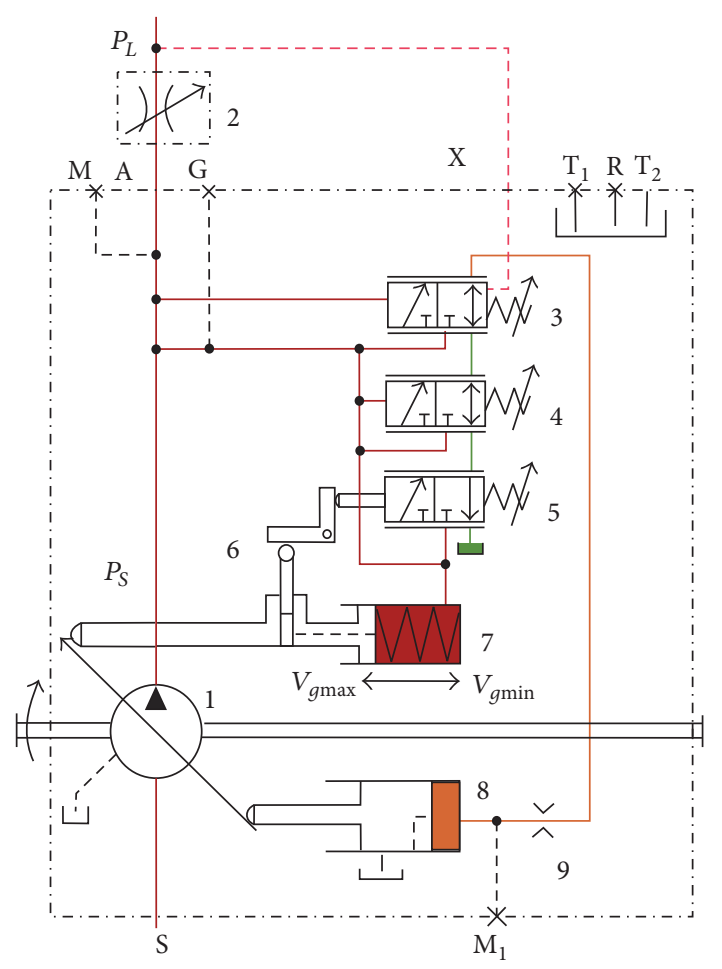

FIGURE 1: Working principle diagram of load sensing variable pump. (1) Main pump, (2) variable orifice, (3) load sensing valve, (4) pressure limiting valve, (5) constant power control valve, (6) roller column mechanism, (7) locating cylinder, (8) servo cylinder, and (9) orifice.

In this paper, the AllV variable pump is taken as the research object. The mathematical model and the simulation test rig of the load sensing pump are established. The response rules of structure parameters and the damping holes arrangement on the pump are studied. The response characteristics of the load sensing pump are studied and optimized.

\section{Working Principle}

The working principle diagram of the load sensing variable pump is shown in Figure 1.

The load sensing is implemented by maintaining specified pressure differential across the variable orifice. Pressures upstream and downstream of the orifice are pump pressure and load pressure, respectively. These pressures act on the side faces of the load sensing valve and shift the valve proportionally to the pressure differential and setting of the centering springs. The valve connections are selected in such a way that increased pressure differential moves the valve spool to its left position; at this time the valve right position is opened and left position is closed. Due to difference between cylinder effective areas and pressures, the pump displacement is decreased if the left position of the load sensing valve is connected to the hydraulic control circuit; conversely the pump displacement is increased if the right position is connected to the hydraulic control circuit. As a result, increased pressure differential across the valve causes the pump to decrease its displacement until it returns to preset value.

Pressure limiting control is a control method to limit the maximum working pressure of the system. The role of the pressure limiting valve is to prevent pump pressure from exceeding the preset value. The pressure limiting valve is set to the desired maximum value. When pump pressure builds up to this value, the valve opens and causes pressure in the right chamber of the valve to decrease opening. The actuator shifts to the right until the pressure returns to the preset value.

\section{Mathematical Modeling}

The common methods to analysis the hydraulic pump are analytic method [17, 18], state space method [19], and bond graph method [20]. In this paper, the analytic method is used to build the dynamic model of the load sensing pump.

(1) Dynamic Equation of the Load Sensing Valve. Dynamic equation of the load sensing valve can be expressed as follows:

$$
\left(P_{s}-P_{L}\right) A_{v}-F_{0}=M_{v} \frac{d^{2} x_{v}}{d t^{2}}+B_{v} \frac{d x_{v}}{d t}+K_{v} x_{v} .
$$

To simplify the computation, let

$$
f_{e}=\left(P_{s}-P_{L}\right) A_{v}-F_{0} .
$$

The transfer function of the load sensing valve can be obtained by Laplace transform

$$
G_{1}=\frac{x_{v}(s)}{F_{e}(s)}=\frac{1 / K_{v}}{s^{2} / \omega_{n v}^{2}+2 \xi_{n v} s / \omega_{n v}+1} .
$$

(2) Dynamic Equation of Swash Plate. Dynamic equation of swash plate [21] can be expressed as follows:

$$
\begin{aligned}
K_{q} x_{v}= & A_{1} \frac{d x_{p}}{d t}+\frac{J V}{A_{1} l_{0}^{2} \beta} \frac{d^{3} x_{p}}{d t^{3}} \\
& +\left(K_{p}+c_{0}\right) \frac{J}{A_{1} l_{0}^{2}} \frac{d^{2} x_{p}}{d t^{2}} .
\end{aligned}
$$

The transfer function of the swash plate can be obtained by Laplace transform

$$
G_{2}=\frac{x_{p}(s)}{x_{v}(s)}=\frac{K_{q} / A_{1}}{s\left(s^{2} / \omega_{n p}^{2}+\left(2 \xi_{n p} / \omega_{n p}\right) s+1\right)} .
$$

(3) Output Flow Characteristics of the Pump. Flow gain equation of the pump [22] can be expressed as follows:

$$
Q_{p}=-K_{Q} n x_{p} .
$$


The transfer function of the pump output flow can be obtained by Laplace transform

$$
G_{3}=\frac{-Q_{p}(s)}{X_{p}(s)}=K_{Q} n .
$$

The pump output flow fluctuation causes the pressure fluctuation, so the differential equation can be expressed as follows:

$$
-Q_{p}+Q_{L}-c_{l} P_{S}=\frac{V_{t}}{\beta} \frac{d P_{S}}{d t} .
$$

Therefore, the transfer function of the pump pressure can be obtained as follows:

$$
G_{4}=\frac{P_{S}(s)}{I(s)}=\frac{1 / c_{l}}{1+s / w_{t}} .
$$

By simultaneous equations (3), (5), (7), and (9), openloop transfer function of the load sensing variable pump can be obtained as follows:

$$
G(s)=\frac{\left(1 / K_{v}\right)\left(K_{q} / A_{1}\right)\left(1 / c_{l}\right) K_{\mathrm{Q}} n A_{v}}{s\left(s / \omega_{t}+1\right)\left(s^{2} / \omega_{n v}^{2}+\left(2 \xi_{n v} / \omega_{n v}\right) s+1\right)\left(s^{2} / \omega_{n p}^{2}+\left(2 \xi_{n p} / \omega_{n p}\right) s+1\right)} .
$$

As can be seen from (10), the open-loop transfer function of the load sensing variable pump consists of two oscillation elements, an inertial element and an amplifying element in series. The response time of the pump is determined by the inherent frequency of the elements, while the oscillation characteristics of the system are determined by the damping coefficient of the elements. The only way to improve the system is to diminish the impact of first-order inertial element and ensure that the second-order oscillation element plays a dominant part in the system. It can be realized by increasing corner frequency of first-order inertial element so as to increase the flow-pressure coefficient of the load sensing valve or reducing the spring stiffness of the load sensing valve and the piston area of variable hydraulic cylinder.

\section{Test Rig Design}

The test rig designed to investigate interaction between an axial-piston pump and a typical control unit, simultaneously performing the load sensing and pressure limiting functions. To assure required accuracy, the pump model must account for such features as interaction between pistons, swash plate, and porting plate, which makes it necessary to build a detailed pump model.

4.1. Test Rig Overview. The test rig schematic diagram of the load sensing variable pump is shown in Figure 2. The pump model is represented by the subsystem named axial-piston pump. The prime mover rotating the pump is simulated with the Ideal Angular Velocity source. The pump output delivery on its way to tank passes through the pipeline and two variable orifices.

The flow control orifice sets the specified flow rate; its opening remains constant during simulation. The load sensing function of the pump must maintain pressure differential across this orifice constant, regardless of pump loading. The pump loading is simulated with the load orifice block. To test control unit response to variable load, the load orifice changes its area during simulation. The change profile is implemented by the Load Signal Builder block.
The control unit in the test rig is represented by the subsystem named pressure/flow control unit. The control unit receives signals on pump output pressure and load pressure, measured after the flow control valve. Based on these pressures, the control unit produces yoke displacement, which affects the angular position of the angled swash plate in the pump. This helps maintain the specified pressure differential across the flow control valve and prevent pump pressure from exceeding the preset value. The basic parameters of the test rig are shown in Table 1.

4.2. Test Rig Model. In this section, the models of main pump and control unit are built, respectively.

4.2.1. Axial-Piston Pump Model. The pump under investigation is an axial-piston pump. The block diagram of the pump model is shown in Figure 3. In Figure 3, S is pump driving shaft, $\mathrm{Y}$ is yoke connected with the inclined plate of the swash mechanism, and $\mathrm{P}$ is pump discharge. Every piston of the pump is represented by a subsystem called piston. These subsystems are identical and are connected to the external ports of the pump model. The suction ports of all pistons (ports A) are connected to the output of a low pressure booster pump, which is simulated with the Ideal Hydraulic Pressure Source block. The output pressure of the booster pump is set to 5 bar. The yoke is connected to the actuator ports of all pistons, thus acting on the angled plate of the swash mechanism. The displacement of the yoke is limited by the hard stop.

4.2.2. Pressure/Flow Control Unit Model. The control unit model is shown in Figure 4, which is built using the 3-Way Directional Valve, Hydraulic Double-Acting Valve Actuator, Pressure-Relief Valve, and Fixed Orifice blocks. Ports Ps and LSP are connected to upstream and downstream of the flow control orifice in Figure 2. The pressure differential of the flow control orifice is set to 20 bar. In Figure 4 the 3-Way Directional Valve lower position must be initially open, to force the pump to increase its displacement at the start of 


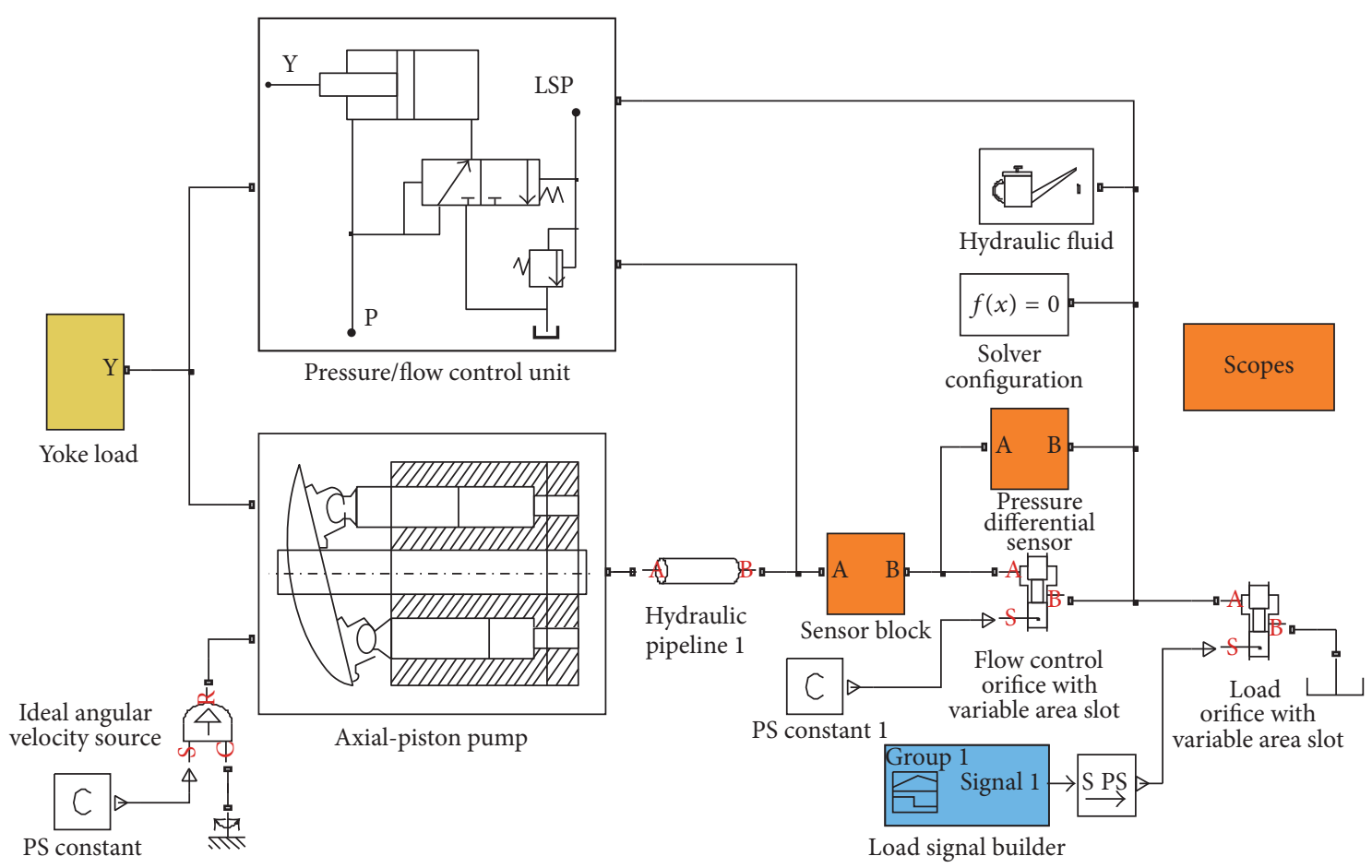

FIgURE 2: Test rig schematic.

TABLE 1: Test rig basic parameters.

\begin{tabular}{lcc}
\hline Number & Name & Parameters \\
\hline 1 & Pump maximum displacement & $7.9 \times 10^{-6} \mathrm{~m}^{3} / \mathrm{rad}$ \\
2 & Pitch radius & $0.05 \mathrm{~m}$ \\
3 & Diameter of Pistons & $0.028 \mathrm{~m}$ \\
4 & Number of pistons & 9 \\
5 & Maximum piston stroke & $0.06 \mathrm{~m}$ \\
6 & Swash plate maximum angle & $0.65 \mathrm{rad}$ \\
7 & Arm length between the actuator and the swash plate pivoting point & $0.056 \mathrm{~m}$ \\
8 & Swash plate actuator stroke & $0.05 \mathrm{~m}$ \\
9 & Diameter of the orifice at the bottom of the piston chamber & $0.007 \mathrm{~m}$ \\
10 & Pump maximum rated speed & $230 \mathrm{rad} / \mathrm{s}$ \\
11 & Maximum pressure & $270 \mathrm{bar}$ \\
12 & Rated flow & $1.1 \times 10^{-3} \mathrm{~m}^{3} / \mathrm{s}$ \\
\hline
\end{tabular}

operation. To perform the load sensing function, pressure increase at the LSP port must open the lower position of the 3-Way Directional Valve and close the upper position of the 3Way Directional Valve. These are the reasons that determined the valve port connections to the system. The remaining load sensing control valve parameters, such as spring stiffness, valve stroke, and valve orifice area, are determined during model workout to ensure required accuracy, stability, and numerical effectiveness.

The pressure limiting function is implemented with the combination of the Fixed Orifice and Pressure-Relief Valve blocks. The Pressure-Relief Valve is set to 250 bar. At this pressure, increased flow through the Fixed Orifice causes pressure at port Yoke of the Hydraulic Double-Acting Valve Actuator to drop, which eventually decreases the displacement of the pump.
4.3. Test Rig Verification. In order to verify the validity of the test rig, the performance of the load sensing variable displacement pump is tested by simulation and experiments.

4.3.1. Simulation Verification. The simulated cycle consists of six elements characterized by different load conditions with the Variable Area Slot block whose opening is controlled with the Load Signal Builder block, as shown in Figure 5 (the load valve is initially opened by $2 \mathrm{~mm}$ ).

The cycle starts with zero opening signal, followed by opening of $2.7,5.4,1,-0.8$, and $2.5 \mathrm{~mm}$. At the start of the cycle, the pump shaft starts rotating at $230 \mathrm{rad} / \mathrm{s}$ with the pump yoke initial position set to $5 \mathrm{~mm}$. The response curves of load sensing variable displacement pump are shown in Figure 6. 


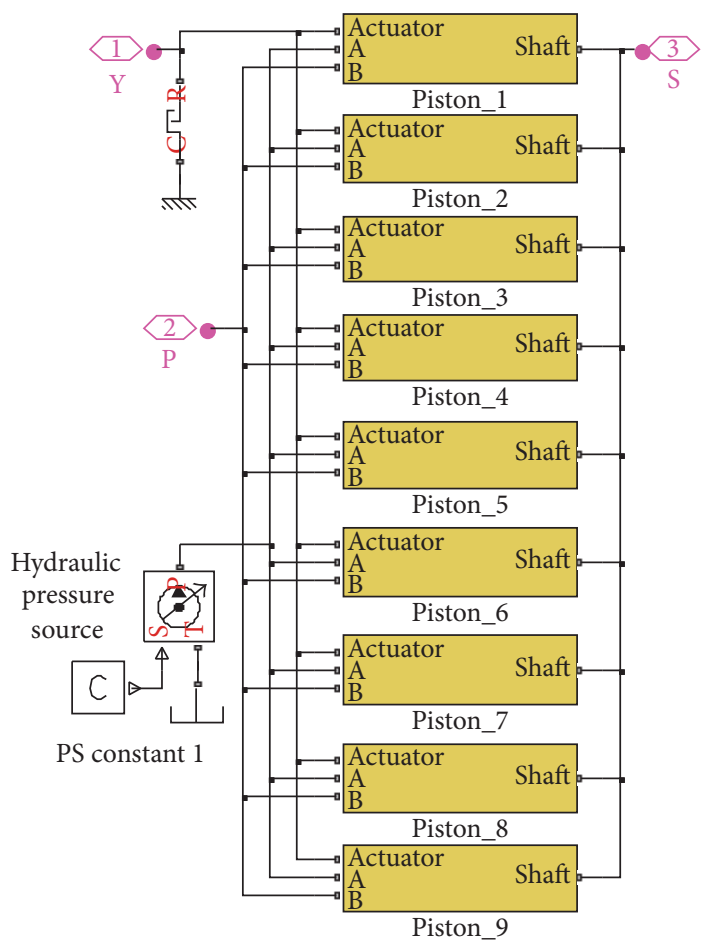

Figure 3: Piston pump model.

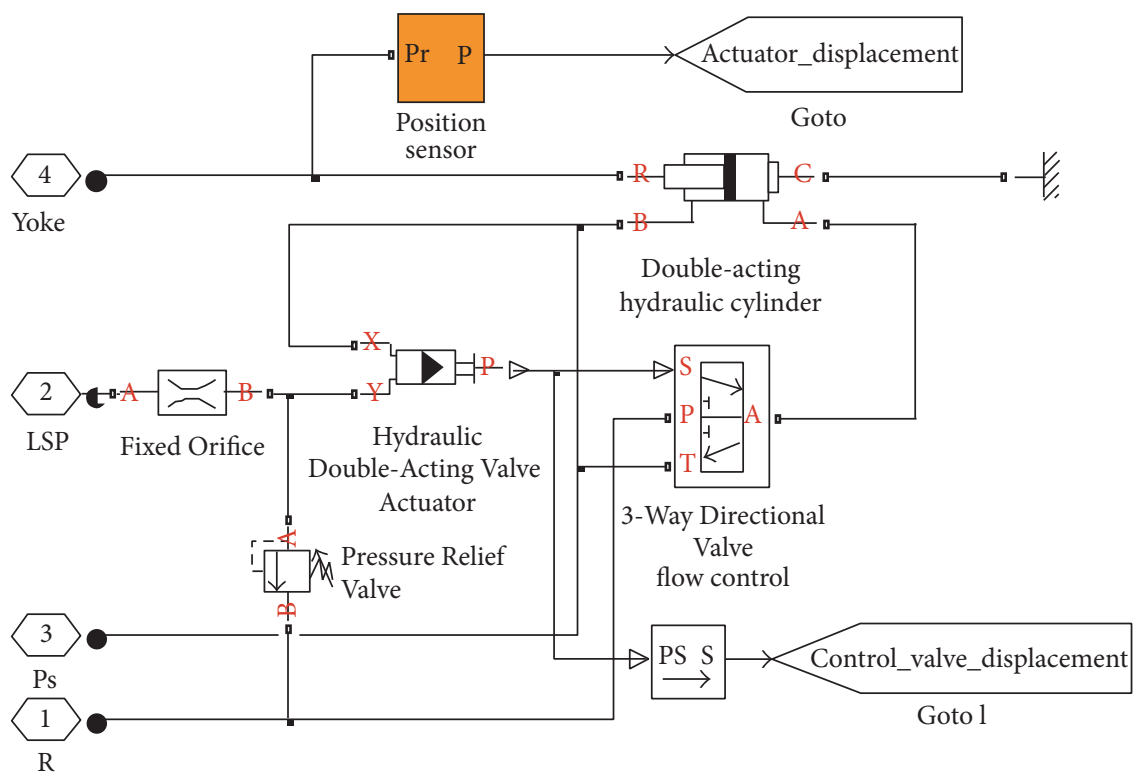

Figure 4: Pressure/flow control unit model.

As can be seen from Figure 6, the servo cylinder starts increasing pump displacement, pump pressure slowly builds up, and the process settles down at $\sim 0.23 \mathrm{~s}$ after the pressure differential across the flow control valve becomes close to preset value; the load sensing valve is opened at this moment. During next three portions of the cycle, the pump maintains practically the same delivery despite changes of the load valve opening. At 2.0 seconds, the load valve is practically fully closed, causing pump pressure to rise. The load limiting function becomes dominant as the pressure reaches 270 bar. The pump returns to the load sensing mode after the pressure falls below the preset value. The simulation results show that the response characteristics of the test rig are consistent with the characteristics of the load sensing variable pump. Therefore, the response characteristics of the load sensing variable pump can be dynamic simulation analyzed by using the test rig. 


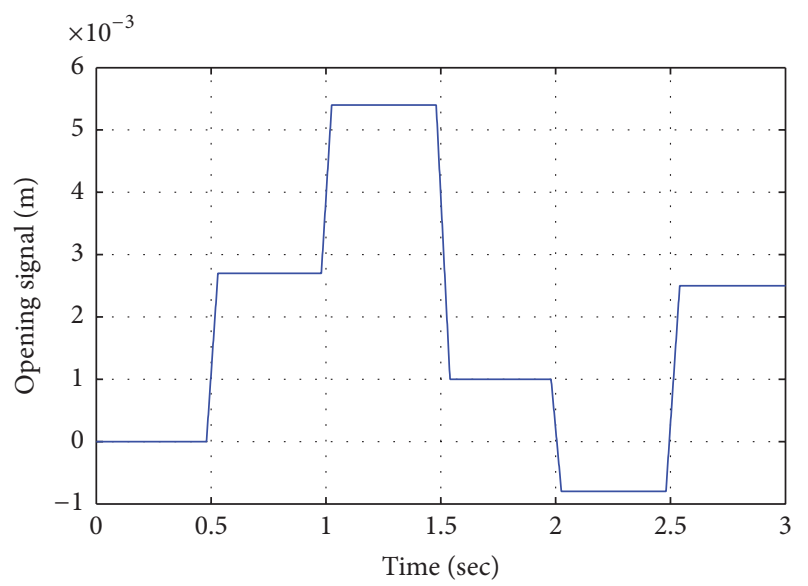

FIGURE 5: Opening of the load-simulating valve versus time.

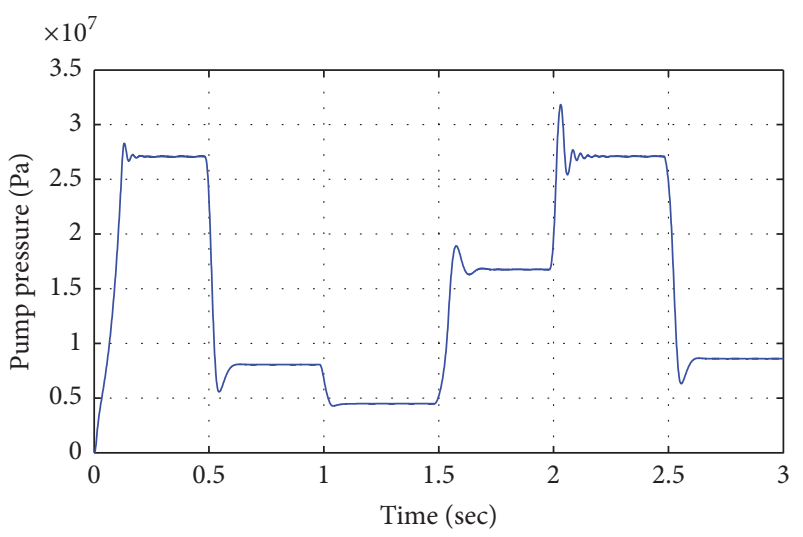

(a) Pump outlet pressure

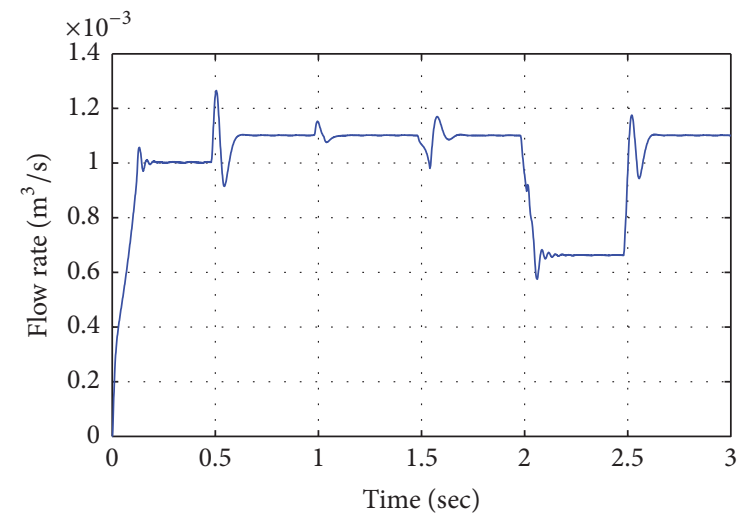

(b) Pump flow rate

FIGURE 6: Response characteristic curves of simulation verification.

4.3.2. Experimental Verification. In order to verify the validity and reliability of the load sensing variable pump simulation test rig, a hydraulic pump experiment system is constructed to measure the actual pump flow under different working pressures and draw pressure-flow characteristic curve. The experimental system is shown in Figure 7.

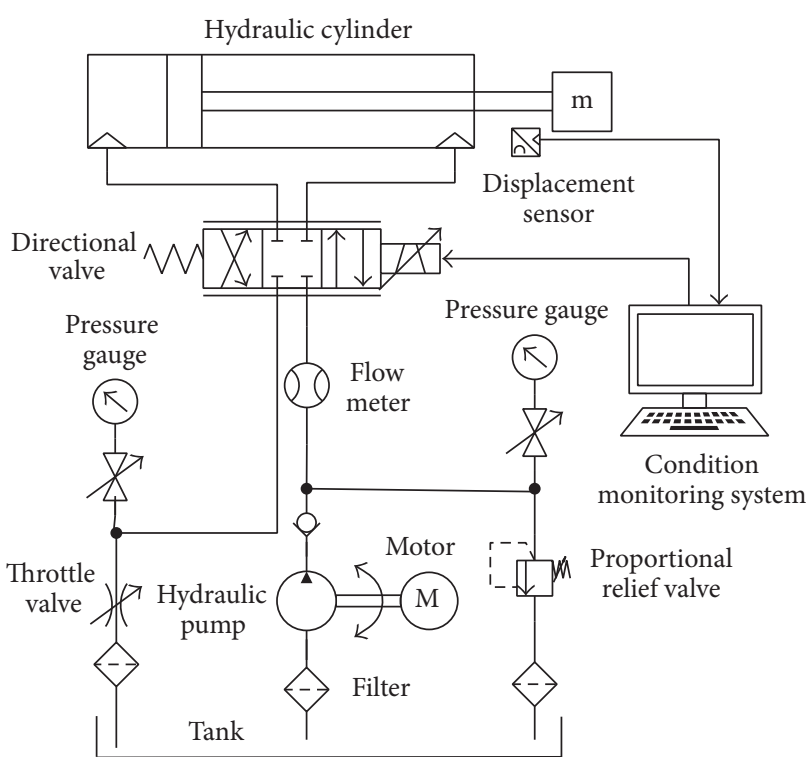

Figure 7: Experimental system schematic of the hydraulic pump.

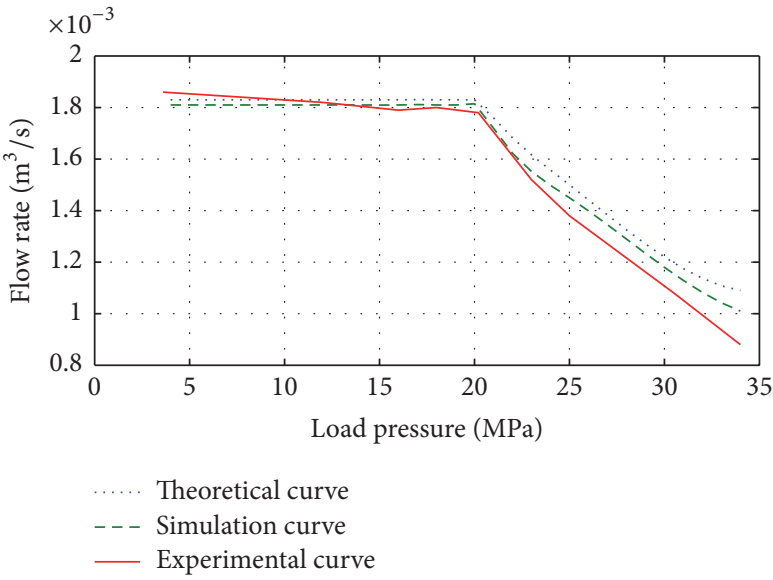

FIGURE 8: External characteristic curve of the pump.

The main experiment steps are as follows:

(1) According to the experimental principle, develop the test rig of the load sensing variable and check the oil pipes carefully.

(2) Adjust the relief valve to the maximum, start the hydraulic pump, and keep the directional valve in the middle position; adjust the pressure of the relief valve to make it be higher than the rated pressure of the hydraulic pump.

(3) Adjust the directional valve to the largest opening and then measure pump no-load flow; through step by step reduce opening of the directional valve to achieve load on the system, and the relevant data under different load pressure is measured.

According to the experimental data, the performance curve of the hydraulic pump is shown in Figure 8. As can be 


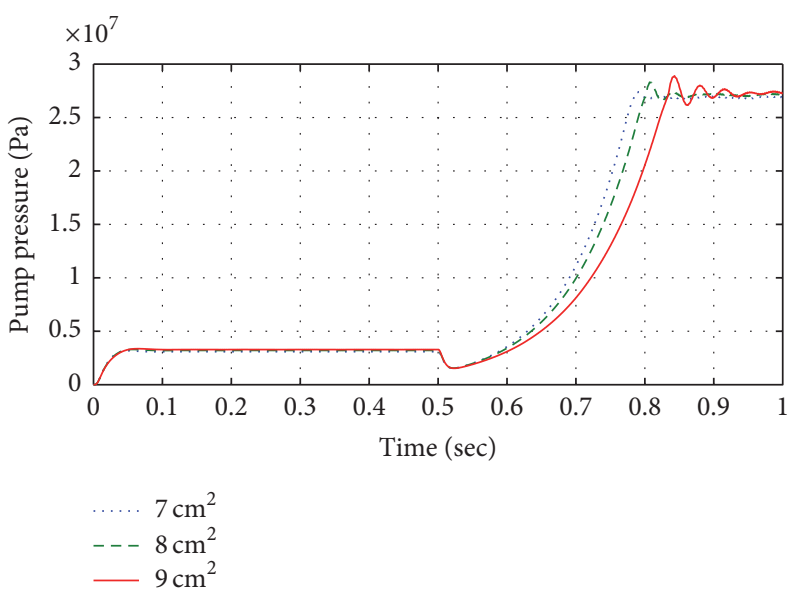

(a) Pump output pressure

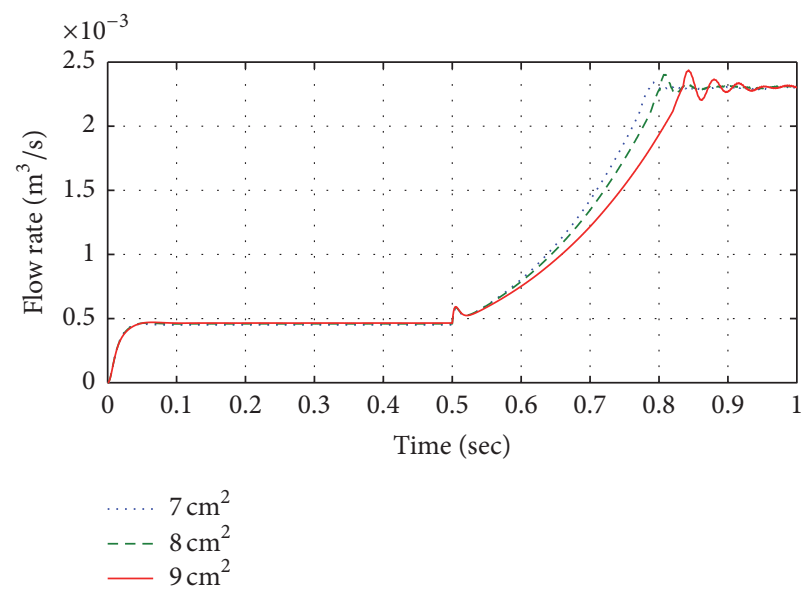

(b) Pump flow rate

FIGURE 9: Response characteristic curves of servo cylinder effective action areas.

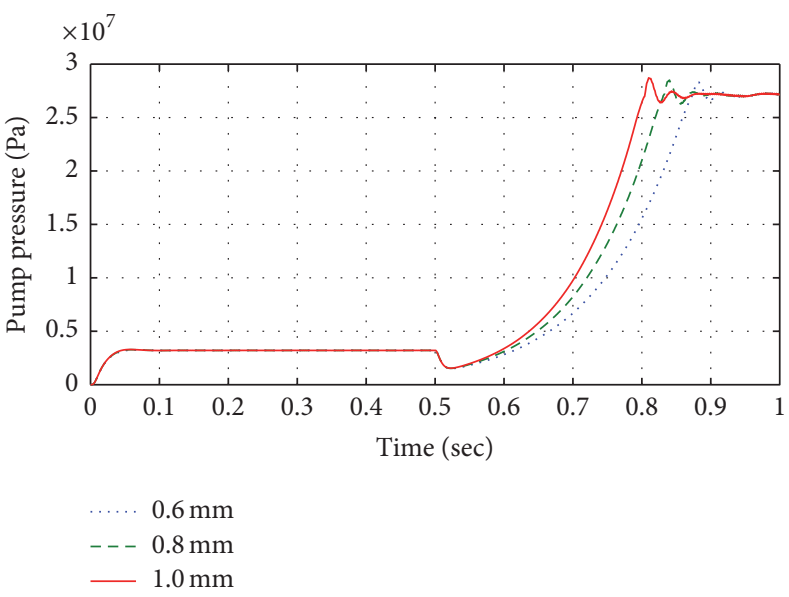

(a) Pump output pressure

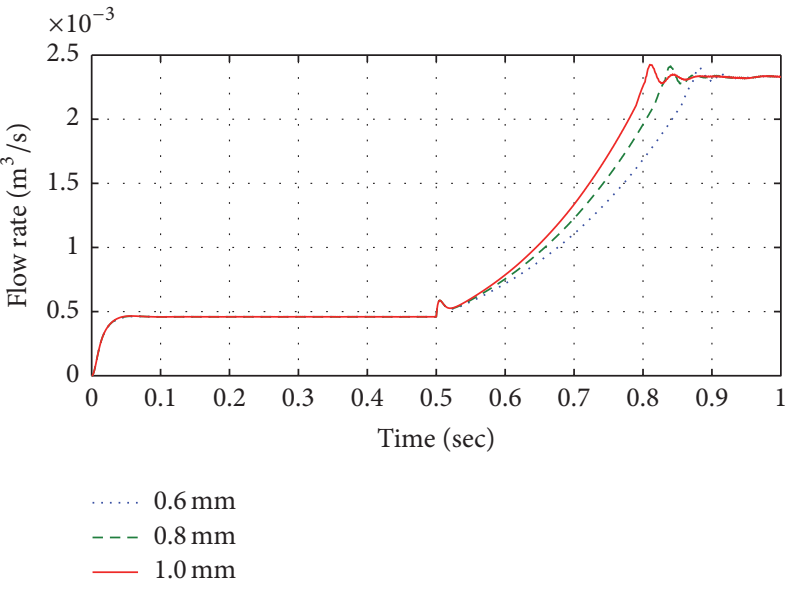

(b) Pump output flow

FIGURE 10: Response characteristic curves of damping holes.

seen from Figure 8, the experimental curve is very close to the theoretical value, and the experimental value is between the actual value and the theoretical value. The validity of the test rig is validated.

\section{Simulation and Optimization}

In this section, the response characteristics rules of the pump key parameters are discussed; then, an optimization scheme for the load sensing variable pump is put forward.

5.1. Simulation Analysis. Through the test rig simulation, the influence rules of the servo hydraulic cylinder effective area and the orifice aperture size are studied.

5.1.1. Response Rules of Effective Area. The spool displacement of load orifice block is set to $2.5 \mathrm{~mm}$. The effective areas of servo cylinder are set to $7 \mathrm{~cm}^{2}, 9 \mathrm{~cm}^{2}$, and $11 \mathrm{~cm}^{2}$, respectively. After 0.5 seconds the step signal is to act on the flow control orifice for 0.5 seconds. The response characteristic curves of the load sensing variable displacement pump are shown in Figure 9 .

As can be seen from Figure 9, step response times of the pump are $0.309 \mathrm{~s}, 0.340 \mathrm{~s}$, and $0.415 \mathrm{~s}$ under three working conditions, respectively. Hence it may be concluded that increasing the effective area of servo hydraulic cylinder causes the pump to decrease its corner frequency, which leads to decrease in response speed.

5.1.2. Response Rules of Orifice Size. The orifice radiuses of servo cylinder are set to $0.6 \mathrm{~mm}, 0.8 \mathrm{~mm}$, and $1.0 \mathrm{~mm}$, respectively. After 0.5 seconds the step signal is to act on variable orifice for 0.5 seconds. The response characteristic curves of the load sensing variable pump are shown in Figure 10.

As can be seen from Figure 10, step response times of the pump are $0.314 \mathrm{~s}, 0.345 \mathrm{~s}$, and $0.422 \mathrm{~s}$, respectively. Hence it may be concluded that the increasing orifice size causes the 


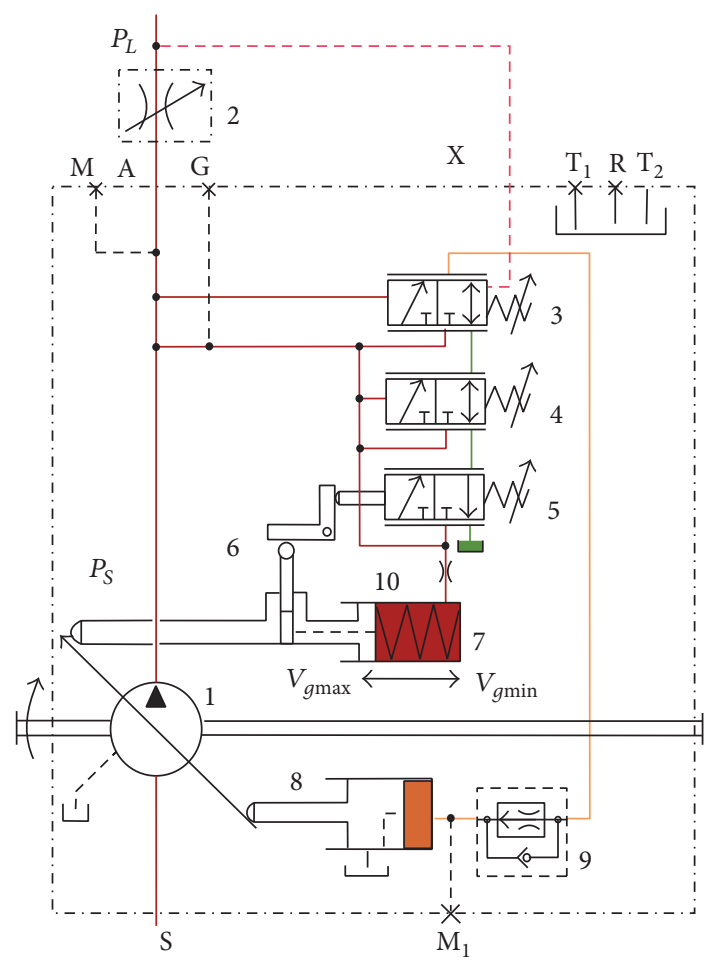

FIGURE 11: Optimized load sensing variable pump control system schematic.

pump to reduce its response time. But at the same time, due to the increase of the damping ratio, the overshoot of swash plate angle is increased which will impact the stability of the system.

5.2. Structure Optimization. The orifice in the original system (see Figure 1) plays the role of the buffer piston reciprocation of the servo cylinder. However, there are problems in the original system that response speed from small to large displacement is slow and the stability of servo hydraulic cylinder is easy to be affected by the pump outlet pressure.

The optimized control schematic of load sensing variable pump is shown in Figure 11. The orifice 9 of the original system is replaced by the one-way throttle valve, which can buffer the pump outlet pressure, increase the pump stability, and improve the response speed of the variable pump. Meanwhile, a new orifice 10 is installed in the locating cylinder inlet, which can buffer the pump outlet pressure and improve the stability of the pump.

Orifice radius of one-way throttle valve 9 is set to $0.8 \mathrm{~mm}$ and the throttle valve 10 is set to $0.9 \mathrm{~mm}$. The step response curves of the original system and the optimized system are shown in Figure 12.

As you can see from Figure 12, the response time of the variable pump has reduced $33.42 \%$ from $374 \mathrm{~ms}$ to $249 \mathrm{~ms}$, and flow overshoot has fell down from $8.9 \%$ to $1.6 \%$ by comparing the optimized system with the original system. Therefore, the response speed and stability of the pump have been improved.

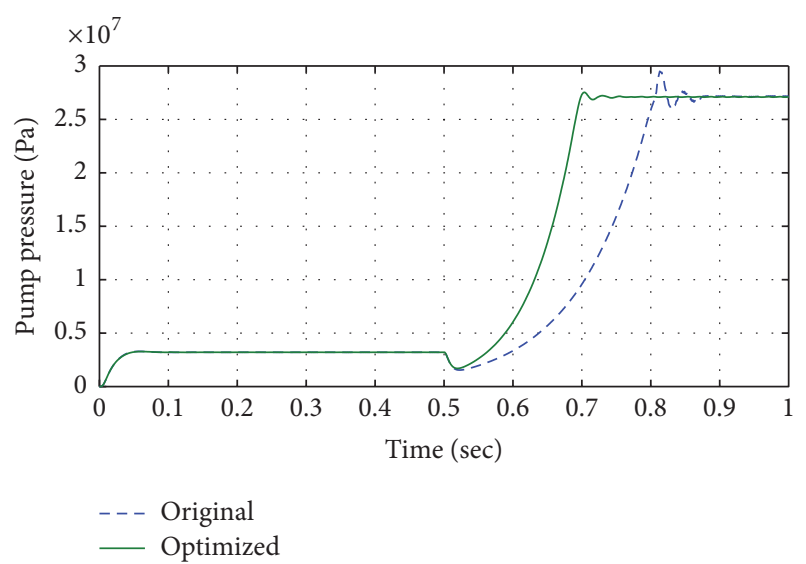

(a) Pump output pressure

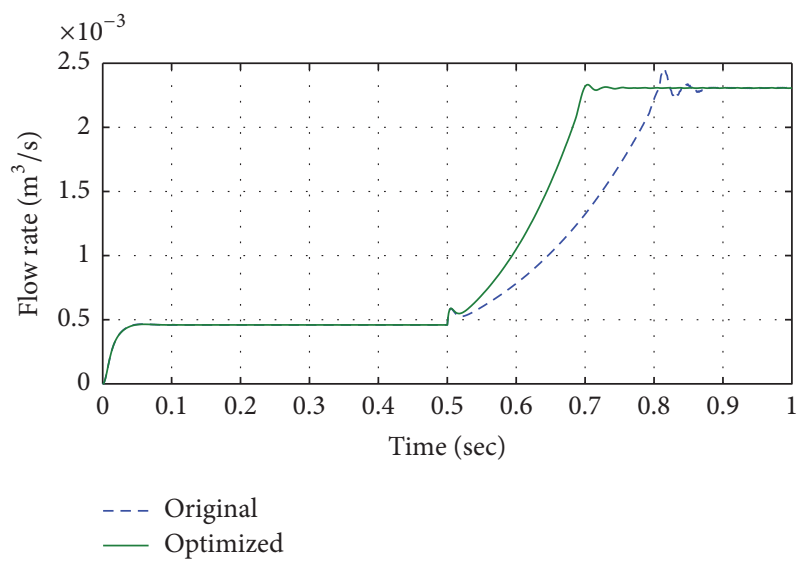

(b) Pump output flow

FIGURE 12: Response characteristic curves of optimized pump system.

\section{Conclusions}

The control principle and dynamic characteristics influence factors of load sensing variable pump are analyzed. The test rig of load sensing variable pump is built. Hence the following conclusions can be drawn.

(1) Based on the transfer function of load sensing variable pump, it may be concluded that the way to improve the response speed of the pump is to reduce the natural frequency of the second-order oscillation element and increase the corner frequency of firstorder inertia element.

(2) The simulation test rig of load sensing variable pump based on the SimHydraulics is verified by comparing the results of the experiment, theory, and simulation. The simulation model provides a reliable platform to study the dynamic characteristics of load sensing variable pump.

(3) The response speed and stability of the load sensing variable pump can be effectively improved by the reasonable structural arrangement and parameters setting. 
Further Research. A prototype of optimized load sensing variable pump should be developed; the performance of the optimized pump should be validated by experiments.

\section{Nomenclature}

$P_{S}:$ The pump outlet pressure

$P_{L}$ : The load pressure

$A_{v}$ : The LS valve control area

$F_{0}$ : The LS valve spring preset pressure

$M_{v}$ : The LS valve spool equivalent quality

$B_{v}$ : The LS valve damping coefficient

$K_{v}$ : The LS valve spring stiffness

$x_{v}$ : The LS valve spool displacement

$\omega_{n v}$ : The natural frequency of the LS valve, $\omega_{n v}=\sqrt{K_{v} / M_{v}}$

$\xi_{n v}$ : The damping coefficient of the LS valve, $\xi_{n v}=B_{v} \omega_{n v} /\left(2 K_{v}\right)$

$K_{q}$ : The flow gain of the LS valve

$K_{p}$ : The flow-pressure coefficient of LS valve

$x_{p}$ : The displacement of servo cylinder

J: $\quad$ The moment of inertia of swash plate and variable piston with respect to the rotating center

$V: \quad$ The volume of servo cylinder large chamber

$A_{1}$ : The area of servo cylinder large chamber

$l_{0}$ : The distance between the center of the servo cylinder and the center of the swash plate

$\beta$ : The effective bulk modulus

$c_{0}$ : The leakage coefficient of servo cylinder large chamber

$\omega_{n p}$ : The natural frequency of the swash plate, $\omega_{n p}=\sqrt{A_{1}^{2} \beta l_{0}^{2} /(J V)}$

$\xi_{n p}$ : The damping coefficient of the swash plate, $\xi_{n p}=\omega_{n p} J\left(K_{p}+c_{0}\right) /\left(2 A_{1}^{2} l_{0}^{2}\right)$

$n$ : The pump speed

$K_{Q}$ : The displacement gradient of the pump

$Q_{L}$ : The load flow

$c_{l}$ : The leakage coefficient of the locating cylinder

$V_{t}$ : The volume of the pump output

$I(s)$ : The flow deviation signal,

$I(s)=-Q_{p}(s)+Q_{l}(s)$

$w_{t}$ : The corner frequency of inertial element, $w_{t}=\beta c_{l} / V_{t}$.

\section{Competing Interests}

The authors declare that there are no competing interests regarding the publication of this paper.

\section{Acknowledgments}

This research is supported by Jiangsu Province Science Foundation for Youths (BK2012061), PLA University of Science and Technology Commission Project (NJCX-RW-20120217), and General Armament Department Pre Research Project (no. 2211).

\section{References}

[1] M. Bojinović, N. Mole, and B. Štok, "A computer simulation study of the effects of temperature change rate on austenite kinetics in laser hardening," Surface \& Coatings Technology, vol. 273, no. 1, pp. 60-76, 2015.

[2] M. Yokoyama, "Automated computer simulation of twodimensional elastostatic problems by the finite element method," International Journal for Numerical Methods in Engineering, vol. 21, no. 12, pp. 2273-2287, 1985.

[3] B. He, L. Han, Y. Wang, S. Huang, and L. Liu, "Kinematics analysis and numerical simulation of a manipulator based on virtual prototyping," International Journal of Advanced Manufacturing Technology, vol. 71, no. 5-8, pp. 943-963, 2014.

[4] M. Xu, J. Ni, and G. J. Chen, "Co-simulation of energy regulation based variable-speed electrohydraulic drive," Procedia Engineering, vol. 15, pp. 1103-1109, 2011.

[5] Y. S. Hong and Y. H. Doh, "Analysis on the friction losses of a bent-axis type hydraulic piston pump," Journal of Mechanical Science and Technology, vol. 18, no. 9, pp. 1668-1679, 2004.

[6] M. Z. Norhirni, M. Hamdi, S. Nurmaya Musa, L. H. Saw, N. A. Mardi, and N. Hilman, "Load and stress analysis for the swash plate of an axial piston pump/motor," Journal of Dynamic Systems, Measurement \& Control, vol. 133, no. 6, Article ID 064505, pp. 2417-2424, 2011.

[7] I.-S. Cho and J. Y. Jung, "A study on the pressure ripple characteristics in a bent-axis type oil hydraulic piston pump," Journal of Mechanical Science and Technology, vol. 27, no. 12, pp. 3713-3719, 2013.

[8] I.-H. Baek, I.-S. Cho, J.-Y. Jung, and L. Hong, "Analysis of piston behavior according to eccentricity ratio of disk in bent-axis type piston pump," Journal of Mechanical Science and Technology, vol. 22, no. 9, pp. 1726-1733, 2008.

[9] J. M. Bergada, S. Kumar, D. L. Davies, and J. Watton, "A complete analysis of axial piston pump leakage and output flow ripples," Applied Mathematical Modelling, vol. 36, no. 4, pp. 1731-1751, 2012.

[10] P. Casoli and A. Anthony, "Gray box modeling of an excavator's variable displacement hydraulic pump for fast simulation of excavation cycles," Control Engineering Practice, vol. 21, no. 4, pp. 483-494, 2013.

[11] N. P. Mandal, R. Saha, S. Mookherjee, and D. Sanyal, "Pressure compensator design for a swash plate axial piston pump," Journal of Dynamic Systems, Measurement, and Control, vol.136, no. 2, pp. 167-175, 2013.

[12] B. Xu, J. Zhang, and H. Yang, "Investigation on structural optimization of anti-overturning slipper of axial piston pump," Science China Technological Sciences, vol. 55, no. 11, pp. 30103018, 2012.

[13] A. Roccatello, S. Mancò, and N. Nervegna, "Modelling a variable displacement axial piston pump in a multibody simulation environment," Journal of Dynamic Systems, Measurement \& Control, vol. 129, no. 4, pp. 456-468, 2007.

[14] J. X. Zhu, Z. X. Zhu, P. Dai, and G. M. Yu, "Analyzing and optimizing response performances of load sensitive pump," Mechanical Science and Technology for Aerospace Engineering, vol. 34, no. 6, pp. 867-871, 2015. 
[15] D. Lovrec, M. Kastrevc, and S. Ulaga, "Electro-hydraulic load sensing with a speed-controlled hydraulic supply system on forming-machines," International Journal of Advanced Manufacturing Technology, vol. 41, no. 11-12, pp. 1066-1075, 2009.

[16] S. H. Cho and P. Noskievič, "Position tracking control with loadsensing for energy-saving valve-controlled cylinder system," Journal of Mechanical Science and Technology, vol. 26, no. 2, pp. 617-625, 2012.

[17] D.-K. Lim, K.-P. Yi, D.-K. Woo et al., "Analysis and design of a multi-layered and multi-segmented interior permanent magnet motor by using an analytic method," IEEE Transactions on Magnetics, vol. 50, no. 6, pp. 1-8, 2014.

[18] M. Akhmet and A. Zafer, "Controllability of two-point nonlinear boundary-value problems by the numerical-analytic method," Applied Mathematics \& Computation, vol. 151, no. 3 , pp. 729-744, 2004.

[19] W. Q. Chen and K. Y. Lee, “Three-dimensional exact analysis of angle-ply laminates in cylindrical bending with interfacial damage via state-space method," Composite Structures, vol. 64, no. 3-4, pp. 275-283, 2004.

[20] A. Alabakhshizadeh, Y. Iskandarani, G. Hovland et al., "Analysis, modeling and simulation of mechatronic systems using the bond graph method," Modeling Identificatione Control, vol. 32, no. 1, pp. 35-45, 2011.

[21] T. Iwatsubo and T. Nishino, "An experimental study on the static and dynamic characteristics of pump annular seals with two phase flow," Japanese Journal of Crop Science, vol. 47, no. 3, pp. 431-437, 1993.

[22] V. I. Forental, M. V. Forental, and F. M. Nazarov, "Investigation of dynamic characteristics of the hydraulic drive with proportional control," Procedia Engineering, vol. 129, pp. 695-701, 2015. 


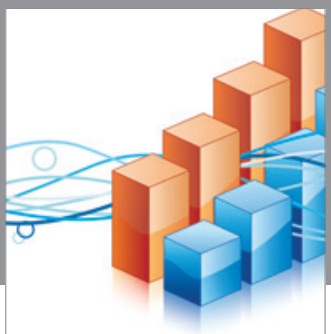

Advances in

Operations Research

vatem alat4

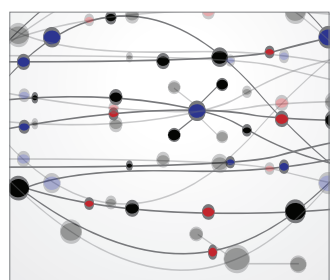

\section{The Scientific} World Journal
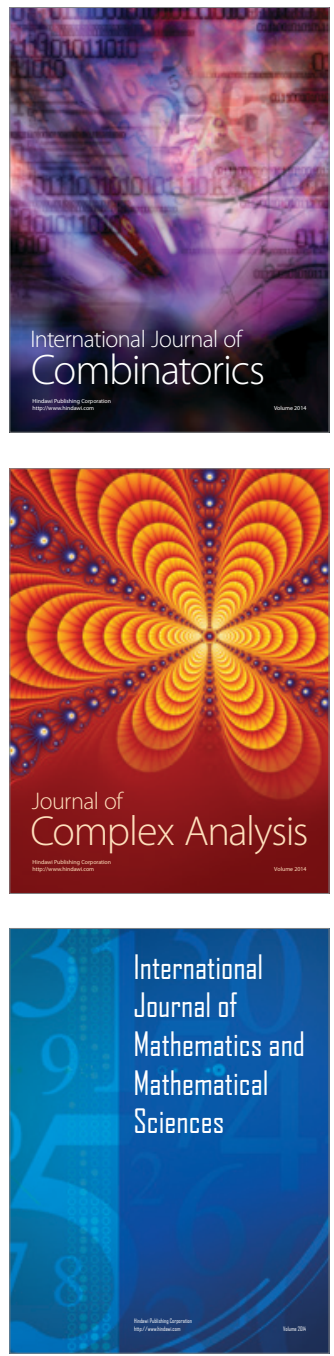
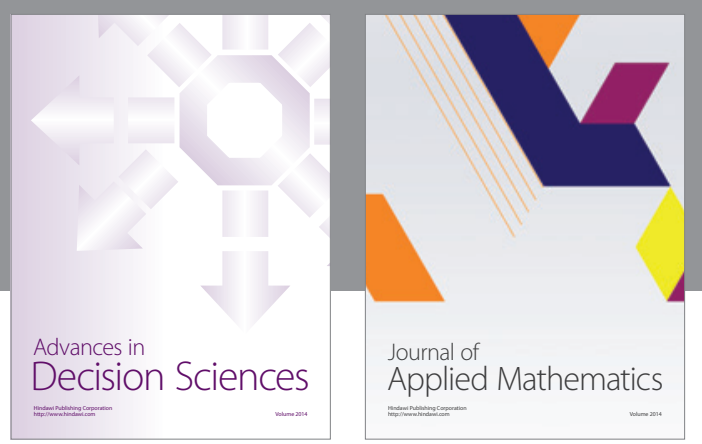

Algebra

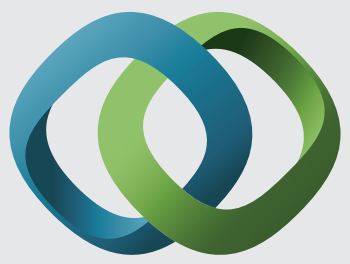

\section{Hindawi}

Submit your manuscripts at

http://www.hindawi.com
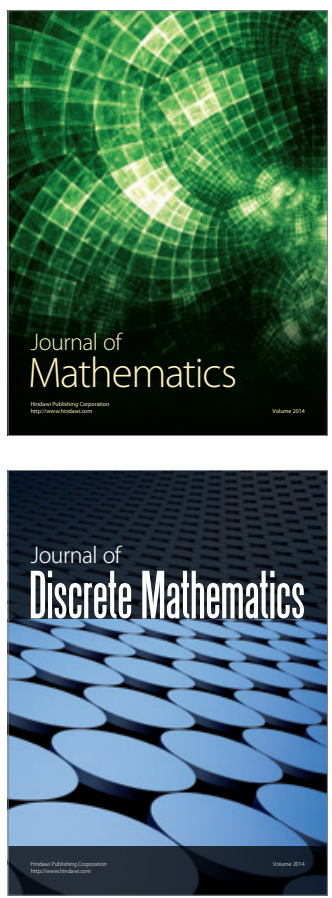

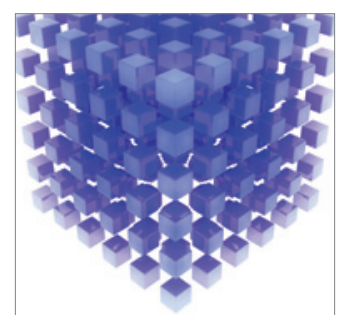

Mathematical Problems in Engineering
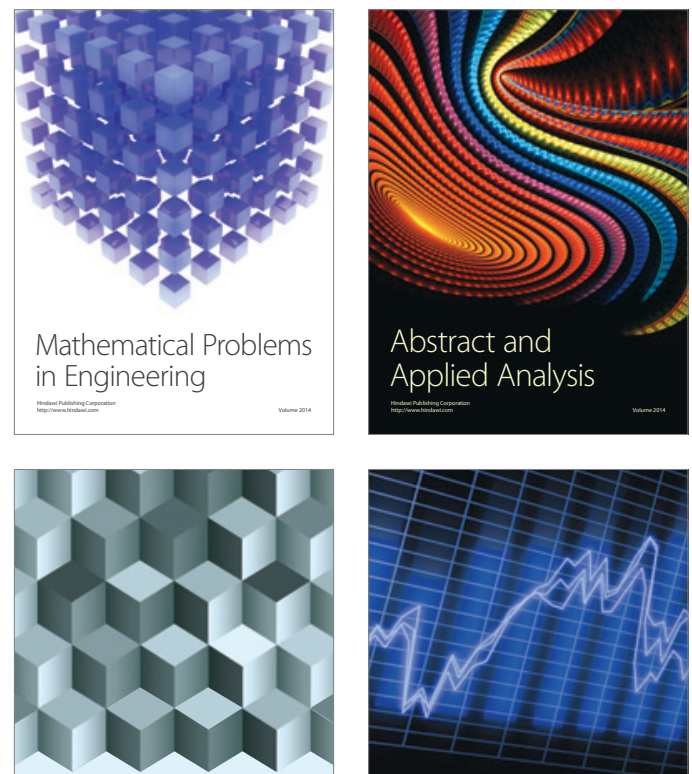

Journal of

Function Spaces

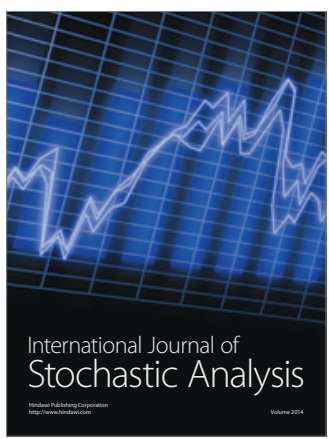

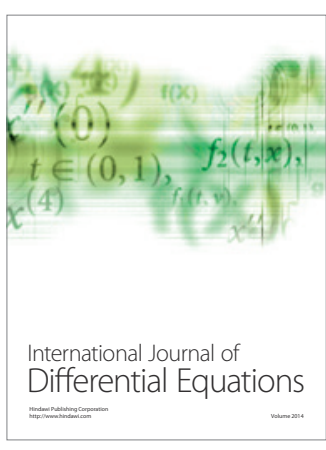
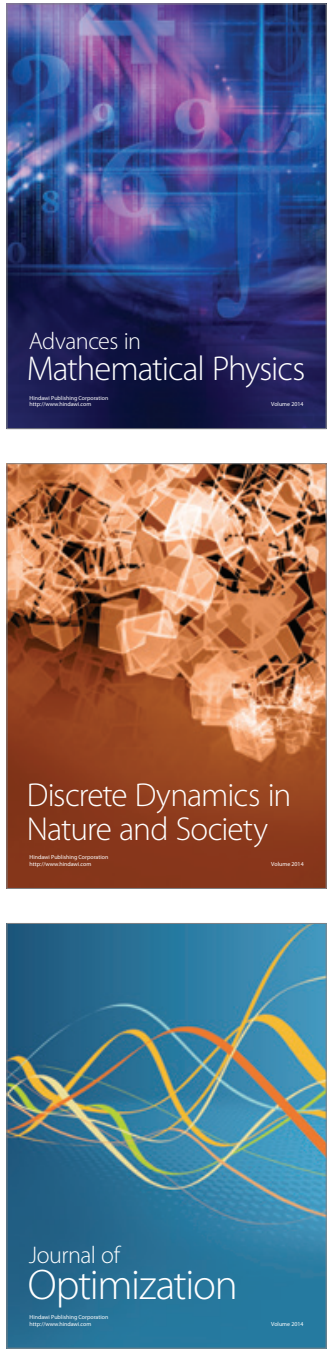